\title{
Spatial Analysis of Road Network in Mongolia
}

\author{
Urantamir Gankhuyag ${ }^{1, *}$, Altanbagana Myagmarsuren ${ }^{1}$, Bayartulga \\ Altankhuyag ${ }^{1}$ \\ ${ }^{1}$ Institute of Geography and Geoecology, Mongolian Academy of Sciences, Ulaanbaatar, Mongolia \\ *Corresponding author. Email: urantamirg@mas.ac.mn
}

\begin{abstract}
In general, road networks of Mongolia have not been developed in accordance with certain theoretical approaches to the transport network and are not economically viable. For instance, the intensity of the road network declines as we move away from Ulaanbaatar. Therefore, it is relevant to analyze and evaluate the current road network and identify opportunities for further development. The purpose of this study is to analyze a Mongolian road network based on the methodology of spatial analysis of the transport network and to identify opportunities for further development. In the spatial analysis of the Mongolian road transport network, the links connecting the nodes are relatively inefficient. Due to the rough terrain in the western part of the country, transportation time and costs have increased. Nodes around Ulaanbaatar have a good level of accessibility, and the further away they are, the lower the level of accessibility.
\end{abstract}

Keywords: Network analysis, road network, link, node, accessibility

\section{INTRODUCTION}

Mongolia is connected by paved roads from Ulaanbaatar to province centers, in the western and central verticals, and from some mining sites to nearby ports. These road network plans have not been developed with a clear theoretical approach to the transport network and are not economically viable. For instance, the traffic intensity of the road network decreases as we move away from Ulaanbaatar [1]. Therefore, it is important to analyze and evaluate the current road network and identify opportunities for further development.

To reach the goal of the study, we need to conduct a spatial analysis of the road network. Transport network analysis methods are based on a graph theory. The graph theory is based on the coding of networks connected to the field of mathematics and the measurement of their properties, the purpose of which is to represent the structure of the network, not its appearance. Graphic representations consist of networks, nodes, and links. A network is a range of location systems defined as nodes. The node is the number of intersections and the link is the line between the two nodes. There are many different methods of analysis in the transport network, and each method has different approach [2; 3]. Selection of the method for network analysis depends on the purpose of the study.

Among the transport network methods, connectivity analysis is more useful. It has different indices, each of which has own meaning. The most basic characteristics of a transport network are measured by the Alpha Index, Beta Index, and Gamma Index [4]. The network (line) and junction (node) are required to obtain the connection index. These indices are useful for system and traffic analyses to detect changes in network structure $[5 ; 6]$. The beta index $(\beta)$ is used to determine the level of road connectivity [2]. The alpha index $(\alpha)$ is the ratio of the actual number of circuits in a network to the maximum possible number of circuits in that network. The gamma index $(\gamma)$ is a measure of the ratio of the number of edges in a network to the maximum number possible in a planar network $[7 ; 8]$. To analyze the network links, detour index is used. This index is defined as the ratio of the shortest path network distance to the Euclidean or straight-line distance between an origin and destination [5;3].

A shimbel index is used in evaluating concentrated levels of transportation networks in urban transportation analysis, while stochastic timedependent (STD) is applied for estimating road network access. A low node STD value indicates a 
high node availability. The second method is the weighted average travel time (WATT); it indicates the importance of the road network node.

The purpose of this study is to analyze the Mongolian road network based on the spatial analysis methods of the transport network and to determine the current level of development and future trends.

\section{STUDY AREA}

The total length of Mongolia's road network is $112786.7 \mathrm{~km}$. According to the above classification, the length of roads is $14918.7 \mathrm{~km}$ of international and national roads, $96125.3 \mathrm{~km}$ of local roads, $872.7 \mathrm{~km}$ of special purpose or mining roads. Ulaanbaatar city has a road network of $870 \mathrm{~km}$ (Figure 1) [9].

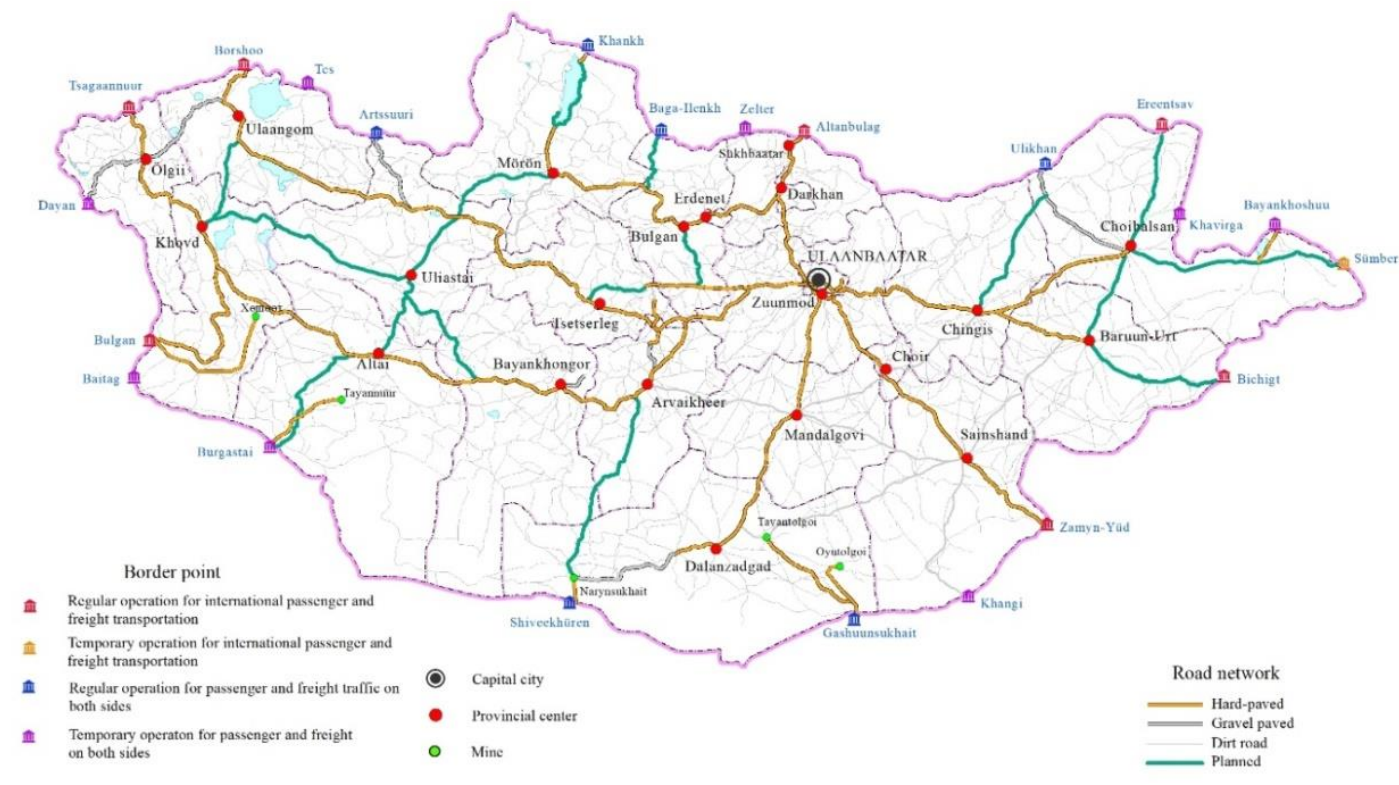

Figure 1. Current status and planning of Mongolia's road network

In order to improve and increase the infrastructure network, the Mongolian Parliament and the Government of Mongolia are implementing the "State Policy on the Road Transport Sector" and the "Steppe Road National Program". The document sets the goal of expanding the international and national road networks and creating a favorable environment for transit traffic in Mongolia to have approximately $6,900 \mathrm{~km}$ of national paved roads by 2021 and 7,500 $\mathrm{km}$ by 2026 . However, it is uncertain whether the design of these roads was done on a scientific basis.

\section{METHODS}

In the present study, we used the Ministry of Road and Transport Development's 2020 road network data. The analysis was conducted according to the below methodological scheme (Figure 2).

For the road network analysis, initially, we selected the routes to be analyzed, and then used a generalization method. The below steps need to be followed to generalize the road network.

- Category: It identifies the object and groups it according to its properties. Mongolia's road network is divided into four categories: International, national, local, and special purpose roads.

- Selecting: Select a specific road class according to the target schedule. In this study, we selected international and national roads.

- Exclude: Exclude short paths of a certain length.

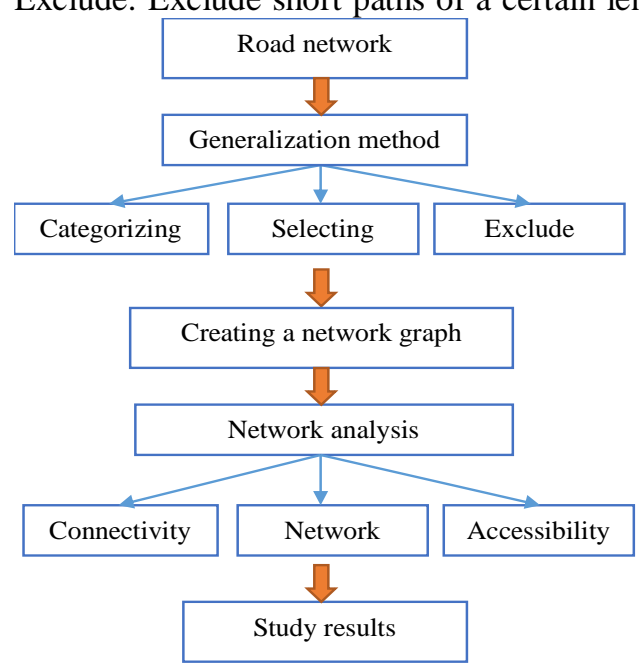

Figure 2. Study methods scheme 
After the generalization to the road network, it is graphically represented using nodes (points) and links (straight lines). There are two basic rules to follow, when converting a real network into a flat graph. They are:

- The most important rule is that each terminal and intersection point is a node.

- Each connected node is then connected in a line segment.
Spatial analysis is possible by representing the network graphically. Based on the graphical representation, the road network connection, network and access were analyzed.

Alpha, beta, gamma, eta, pi index, and network density are used for connectivity analysis. The formulas and explanations for calculating the following indices are shown in Table 1.

Table 1. Indexes used in connectivity analysis

\begin{tabular}{|c|c|c|c|c|}
\hline No & $\begin{array}{c}\text { Index } \\
\text { name }\end{array}$ & Formula & \multicolumn{1}{|c|}{ Description } \\
\hline 1 & $\begin{array}{c}\text { Alpha } \\
\text { index }\end{array}$ & $\alpha=\frac{e-v+1}{2 v-5}(1)$ & $\begin{array}{l}\text { A measure of connectivity which evaluates the number of cycles in a graph in } \\
\text { comparison with the maximum number of cycles. The higher the alpha index, } \\
\text { the more a network is connected. Trees and simple networks will have a value } \\
\text { of 0. A value of 1 indicates a completely connected network. }\end{array}$ \\
\hline 2 & $\begin{array}{l}\text { Beta } \\
\text { index }\end{array}$ & $\beta=\frac{e}{v} \quad(2)$ & $\begin{array}{l}\text { Measures the level of connectivity in a graph and is expressed by the } \\
\text { relationship between the number of links over the number of nodes. Trees and } \\
\text { simple networks have Beta value of less than one. A connected network with } \\
\text { one cycle has a value of 1. }\end{array}$ \\
\hline 3 & $\begin{array}{c}\text { Gamma } \\
\text { index }\end{array}$ & $\gamma=\frac{e}{3(v-2)}(3)$ & $\begin{array}{l}\text { A measure of connectivity that considers the relationship between the number } \\
\text { of observed links and the number of possible links. The value of gamma is } \\
\text { between 0 and 1 where a value of 1 indicates a completely connected network } \\
\text { and would be extremely unlikely. }\end{array}$ \\
\hline 5 & $\begin{array}{c}\text { Network } \\
\text { density }\end{array}$ & $N D=\frac{L}{A} \quad(4)$ & $\begin{array}{l}\text { Measures the territorial occupation of a transport network in terms of km of } \\
\text { links per square kilometers of surface. }\end{array}$ \\
\hline 6 & Pi index & $\Pi=\frac{L}{D} \quad(6)$ & $\begin{array}{l}\text { Average length per link. Adding new nodes will cause a decrease of Eta as the } \\
\text { average length per link declines. Complex networks tend to have a low eta } \\
\text { value. }\end{array}$ \\
\hline
\end{tabular}

$* \mathrm{e}=$ the number of links

Detour index is used for network analysis. This index is defined as the ratio of the shortest path network distance to the Euclidean or straight-line distance between an origin and destination $[5 ; 3]$.

$\mathrm{DI}=\frac{d}{L}$

Where:

$\mathrm{L}=$ Total length of links (road network length),

$\mathrm{d}=$ Euclidian distance (straight line distance between 2 points)

This is a measure of the efficiency of a transport network in terms of how well it overcomes distance or the friction of distance. The closer the detour index gets to 1 , the more the network is spatially efficient. Networks having a detour index of 1 are rarely, if ever, seen and most networks would fit on an asymptotic curve getting close to 1 , but never reaching it. Using the detour index makes it possible to evaluate the city as a whole, but it is more profitable to use it on a private route. $\mathrm{v}=$ the number of nodes

The Shimbel index was used to analyze accessibility. Accessibility analysis is the collection, management, and analysis of spatial and non-spatial data $[11 ; 12]$. Shimbel index is a measure of accessibility representing the sum of the length of all shortest paths connecting all other nodes in the graph. $[3 ; 5 ; 6 ; 8 ; 10]$. The inverse measure is also called closeness centrality or distance centrality.

$A_{i}=\sum_{j=1}^{n} d i j$

Where:

$\mathrm{dij}=$ shortest distance from $\mathrm{i}$ node to $\mathrm{j}$ node, $\mathrm{n}=$ number of nodes

\section{RESULTS AND DISCUSSION}

Within the framework of the study, the international and national roads were selected from the road network of Mongolia and used in the further analysis. The network is represented graphically by 84 links and 63 nodes (Figure 3). 


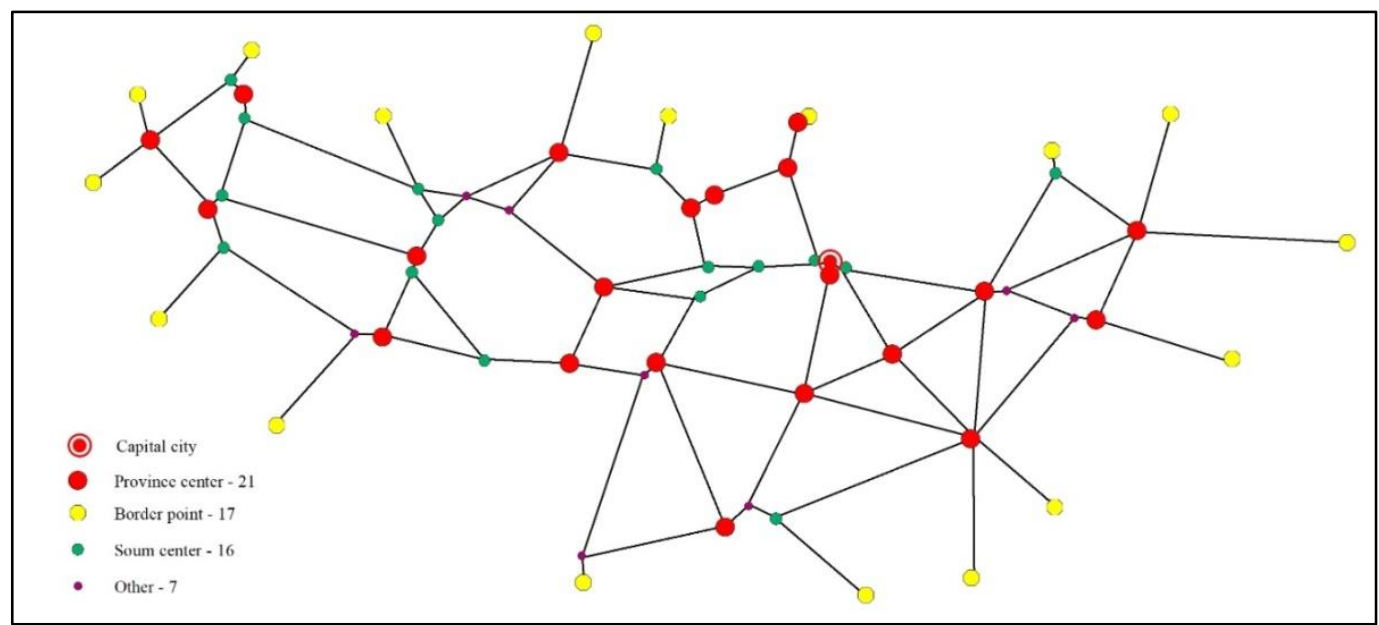

Figure 3. Road network graph

There are 7 nodes in the network, including the capital city, 21 province capitals, 17 border crossings, 16 soum centers, mining sites, and no settlements.
This indicates that the network planning is not fully integrated with the urban area (Figure 3).

Table 2. Based on the above links and the number of nodes, the road network connection status

\begin{tabular}{|l|l|l|l|}
\hline No & Criteria & $\begin{array}{l}\text { Criteria } \\
\text { value }\end{array}$ & Description \\
\hline 1 & Alpha index & 0.18 & Low network connectivity \\
\hline 2 & Beta index & 1.33 & $\begin{array}{l}\text { The nodes are well connected to the network. Nodes are required to be } \\
\text { added }\end{array}$ \\
\hline 3 & Gamma index & 0.45 & The connectivity directly to the node is moderate \\
\hline 4 & Network density & 0.01 & Low road network density \\
\hline 5 & Eta index & 186.0 & The average distance between nodes is moderate \\
\hline 6 & Pi index & 5.2 & The development of network connectivity is moderate \\
\hline
\end{tabular}

\subsection{Network analysis}

The detour index for the study area is 0.87 percent. When we calculate the detour index for each road route, the roads in the western part of the country, such as the
Altai Mountains and the Khangai Mountains, have the highest obstruction $(0.80 \%)$. It increases travel time and cost of transporting goods and passengers in the western part of the country (Figure 4).

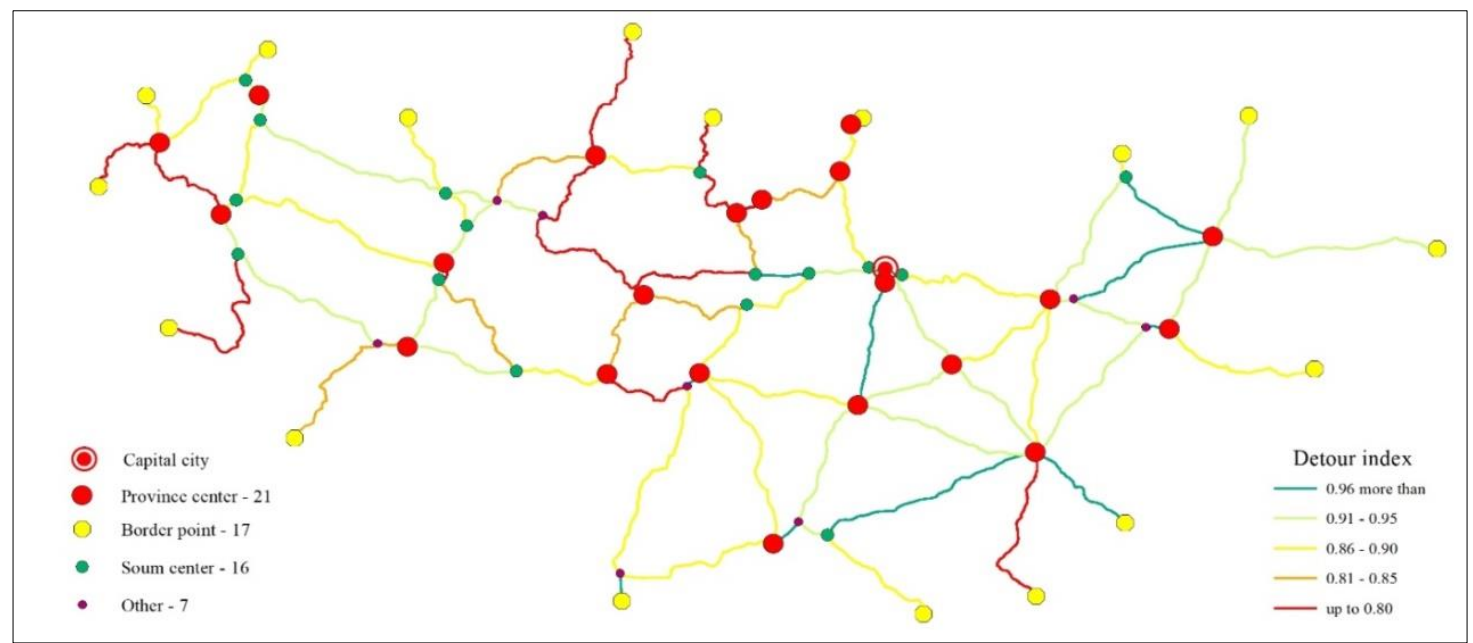

Figure 4. Detour index 


\subsection{Accesibility analysis}

The road network consists of 63 nodes. We calculated the shortest distance matrix for each of these nodes, and the shimbel index was used to estimate the node accessibility.

As a result of the analysis, Ulaanbaatar and its surrounding nodes, such as Darkhan, Chinggis, Choir, Tsetserleg, Arvaikheer, and Erdenet, have good accessibility rates of less than 350 , but the farther away from Ulaanbaatar, the lower the accessibility (Figure 5). It is a form of transport network created by radiation from a single center and is the least efficient version of spatial planning of a transport network.

The current road network plans are designed to support a single-center radiated transport network, which makes it necessary to restructure the network.

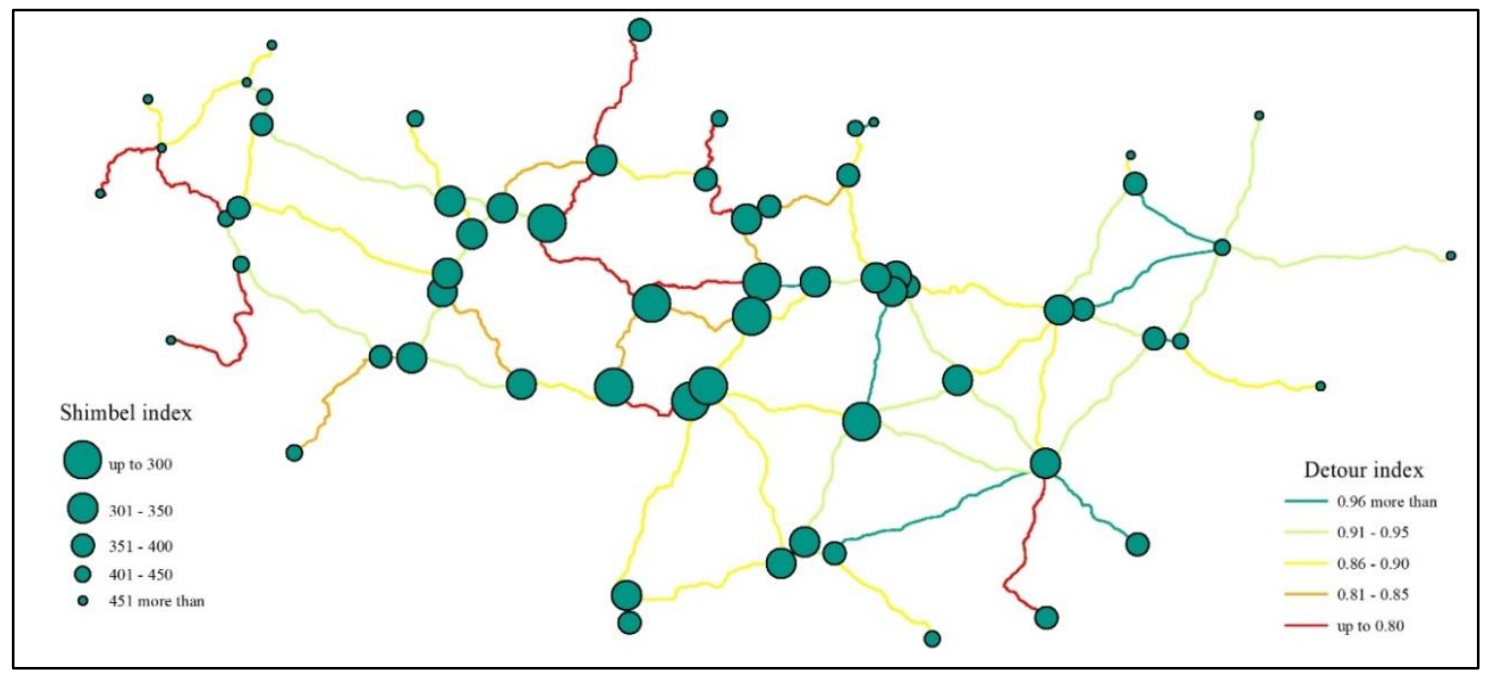

Figure 5. Accessibility map

The current development trends of the road network, our research shows that it is developing in a centralized manner. This confirms other researchers' results that the transport network is developing as a centralized model. The Government of Mongolia is pursuing a policy of decentralization and regional development. Therefore, there is a need to develop nodes that can compete with Ulaanbaatar in the west and east of the country. Therefore, the spatial planning of the transport network can be developed in a comprehensive manner in accordance with the development of cities and regions. To do this, it is necessary to consider a theoretical approach to development based on the axis of the transport network.

\section{CONCLUSIONS}

An analysis of Mongolia's road network led to the following conclusions.

- In the spatial analysis of the Mongolian road transport network, the links connecting the nodes were relatively inefficient. Some of the nodes were located in areas where there were no settlements, indicating that the network planning was not fully integrated with the urban area.
- Due to the rough terrain in the western part of the country, transportation travel time and costs increased.

- Nodes around Ulaanbaatar had a good level of accessibility, and the further away they are, the lower the level of accessibility.

The development of Mongolia's transport network was relatively inefficient and incoherent with regions and urban areas. Therefore, it is significant to use an axial-based model to improve the spatial structure of the road network.

\section{ACKNOWLEDGMENTS}

This study was conducted as part of a basic research project entitled "Renovation of the Fundamentals of the Regional Theory of Mongolia and the Unified Methodology". We would like to thank the scientists and researchers who provided indepth assistance in conducting the research.

\section{REFERENCES}

[1] M. Altanbagana, S. Tuchiya, T. Bazarkhand, B. Kherlenbayar, G. Urantamir, T. Otgonkhuu, D. Khishigdorj, B. Zoljargal, B. Natsagsuren, P. 
Tseyenkhand and B. Solongo, "Renewing and Developing of theoretical foundations, integrated approaches and methodology of the regional development of Mongolia, 2019-2020," 2021.

[2] A.A. Obafemi, S. O. Eludoyin and R. D. Opara, "Road Network Assessment in Trans-Amadi, Port Harcourt in Nigeria Using GIS," International Journal for Traffic and Transport Engineering, 2011, pp. 257-264.

[3] C. Ducruet and J. P. Rodrigue, "Graph Theory: Measures and Indices," in The geography of transport systems, Routledge, 2013, pp. 312-317. ISBN: 978-0-415-82253-4

[4] J. P. Rodrigue, C. Comtois and B. Slack, The geography of transport systems, Third edition ed., Routledge, 2013. ISBN: 978-0-415-822534

[5] D. Levinson, "Network Structure and City Size," PLoS ONE Journal, vol. Volume 7 , no. Issue 1, 2012.

DOI: https://doi.org/10.1371/journal.pone.0029721

[6] K. Lee, "Integrated Approach of Spatial Metrics by Graph-based Road Network on Remotely Sensed Imagery for Urban Transportation Planning," 2005.
[7] G. E. Kofi, "Network based indicators for prioritizing the location of a new urban transport connection: Case study Istanbul, Turkey," 2011.

[8] K. Lee and K. H. Chi, "Uses of High-Resolution Imagery for Urban Transportation Application: Quantitative Indices Extraction Approaches," 2004.

[9] Ministry of Road and Transportation Development of Mongolia, "Statistics of Road and Transport," 2020.

[10]R. V. Vinod, B. Sukumar and A. Sukumar, "Transport Network Analysis of Kasaragod Taluk, Kerala Using GIS," 2003.

[11]P. Morgado and N. Costa, "Geographic networks analysis A graph-based model for analyses the roads networks impact on land cover," Proceedings of 7VCT, Lisbon, 2011, pp. 223229.

[12] S. Liu and X. Zhu, "Accessibility Analyst: an integrated GIS tool for accessibility analysis in urban transportation planning," Environment and Planning B: Planning and Design, 2004, vol. 31, pp. 105-124. DOI: https://doi.org/10.1068/b305 